\title{
THE BRITISH
}

\section{JOURNAL OF DERMATOLOGY.}

\author{
OCTOBER, 1895.
}

\section{DIET IN THE ETIOLOGY AND TREATMENT OF DISEASES OF THE SKIN.}

BY WALTER G. SMITH, M.D.,

President of the Royal College of Physicians of Ireland, Physician to Sir Patrick Dunn's Hospital, Dublin.

Dr. Aluan Jamieson, in his careful paper, has dealt fully with the kinds of food which appear to have a tendency to induce individual skin diseases, and with the forms of cutaneous disease which may bo considered to be influenced or caused by a particular dietary or by special elements in our food, and he has given us useful hints upon treatment.

The fow remarks which I shall offer to you may be taken as complementary to his. I propose to dwell rather upon the limitations of our knowledge, and the imperfection of our data, in the hope that clearer views may emerge from our discussion.

Let me, in the first instance, ask, "Have we any certain or exact scientific knowledge of the influence of diet in the causation of diseases of the skin?"

The belief in the potency of this influence is universal with the laity, and widely acknowledged by the profession generally. But the practice of physicians is partly traditional, and is, unfortunately, not always based upon real conviction or sound knowledge, and many circumstances conspire to tempt them to give formal advice which rests upon a slender foundation. The present opportunity seems a

voL. vII. 
suitable time to re-examine the groundwork of our belief, and it may fairly be expected that the discussion to follow will result in a better definition of our position as medical advisers upon dietetics towards our clients - the public.

I start with the two propositions, that the real infuence of diet in the causation of shin diseases is a small one, much less than it is credited with; and, that our substantial knouledge of the subject is very limited.

Fundamentally the action of food and of drugs is to be explained upon similar general principles.

But great as are the difficulties of forming a correct judgment of the mode of action of a drug, still greater are the complexities which surround questions of dietetics in the causation of cutaneous affections. We are always and in all places confronted with the problem of the idiosyncrasy of the individual, which is a real and perplexing difficulty, and should make us more cautious in formulating cut-and-dry rules for the guidance of our patients' stomachs.

In very many cases an intelligent and temperate patient knows, or ought to know, better than his doctor what suits him and what aggravates his complaint. And I heartily endorse Sir William Roberts' simple and sensible rule of conduct, viz. :-

"It may be regarded as certain that any food, or food-accessory, the use of which is followed by a sense of discomfort, is not beneficial to that individual." ("Dietetics," p. 106.)

And, conversely, as Pye-Smith puts it, "What most people eat is for most people wholesome, and what a natural appetite finds appetising seldom disagrees."

The tendency of modern inquiries has been largely towards the more exact determination of etiological factors. Hence we have been gradually led to.minimise laying stress upon vague and indefinite conceptions, such as diatheses and the like, and of these vague eauses diet is, I think, one, so far as the skin is concerned.

Moreover, the rise and progress of bacteriology has profoundly modified our notions of the cause of many diseases of the slin and influenced our treatment. I need only allude to the pathology of boils, carbuncles, and acute suppuration generally.

Although it is by no means proven that eczema, and even less, psoriasis, are parasitic diseases, still the mere ventilation of such a 
possible cause for these affections tends to throw into the background loose speculations and traditional surmisings as to the effect of dietetic causes in originating diseases of the skin.

We may picture to ourselves four modes or ways, at least, in which diet may possibly influence the skin.

I. Through the general nutrition of the body. Nutrition is influenced in a very subtle manner by the quality of the food (Roberts), and insufficient or improper food lowers the tone of all the tissues, skin included.

Under such conditions we meet with scorbutic and purpuric affections. Destructive and pyogenic microbes find a more suitable soil whereon to fasten, and hence a greater liability to pustular and gangrenous developments.

The fungus of "thrush" lies in wait for debilitated constitutions, and favus is more common among the neglected and ill-fed poor.

II. By acting as a reflex stimulus from the gastro-intestinal tract. This is doubtless the most common mode.

The physiological relationship between the skin and the digestive mucous membrane is incontestable, and proofs are abundant.

Over-eating, on the one hand, and on the other, the use of unsuitable, indigestible, or irritating articles of diet are frequently followed by either neurotic or vaso-motor disturbance in the skin, e.g., urticaria.

The skin affections producible in this way are all transitory, and disappear spontaneously, as a rule, when the causes cease to act.

Many people eat far too much and overload their digestive capacity. And some of them would pay a worse penalty than they do were it not for the dinner pill, the morning saline, or the occasional visit to Carlsbad.

Three practical considerations flow from these thoughts, viz., (a) The utility of purgatives in such cases. (b) The importance of good cookery in avoiding or overcoming dietetic irritation. (c) The due regulation of the diet as to quantity and kind.

III. By absorption into the blood of irritating substances, or, of products of chemical change, which indirectly affect the skin.

In this direction we may look for explanation, in part at least, of the occasional injurious effects of tinned and preserved foods. 
Pathogenie bacteria may undoubtedly enter the body with articles of diet.

We are all familiar, by daily observation, with the hyperæmia of the skin which ensues upon full doses of alcohol.

IV. The skin may suffer in virtue of being one of the channels or avenues of elimination.

Certain drug eruptions, arising from volatile oils or oleo-resins, e.g., copaiba, cubebs, and turpentine, are perhaps explicable upon this hypothesis. And, upon similar grounds, we caution our patients against the use of highly seasoned foods and spices (i.e., volatile oils) in erythematous and acute inflammatory affections of the skin.

To turn now to another aspect of the question, viz., diseases of the skin in relation to diet. We can at once make three groups:-

1. Cutaneous diseases liable to originate in, or acknowledged by common consent to be materially influenced by diet. 2. Cutaneons diseases possibly, but not proven to be, influenced by diet. 3. Cutaneous diseases certainly not affected by diet, e.g., Herpes, Pemphigus, Lichen ruber, Ichthyosis, Ringworm, etc.

In class 1 we may instance:-(a) Erythema, certain forms of,-(b) Urticaria. (c) Pruritus. (d) Acne rosacea. (e) Acne vulgaris, perhaps?

Bulkley states that in some persons crops of acne follow the free use of buckwheat ("Eczema," 2nd Edition, page 291). And PyeSmith affirms that in some patients a fresh outbreak of follicular inflammation can be produced at will by eating "crystallized" fruits, strawberry jam, or orange marmalade. (Brit. Journ. of Dermat., July, 1895.)

In class 2 may be placed Psoriasis, most cases of Eczema, and of Acne vulgaris.

Eczema in children is very frequently attributed to dietetic influences, such as too free use of sugar, or even of milk. But, for my part, I quite concur with Dr. Cheadle in never having been able to satisfy myself that Eczema is a diet disease. (Cheadle, "Artificial Feeding of Infants," page 161.)

Many infants attacked with severe eczema are of a ruddy colour, have a good appetite, and with all the appearance of good health.

It is the present habit to ascribe many skin diseases to gout, and we hear every day of "gouty eczema," "gouty psoriasis," and the 
like; and various queer nondescript ailments are shunted off the main line to a gout siding. Patients ask for and expect to get from us minute directions about their culinary arrangements. Yet few English practitioners, conversant with diseases of the skin, would go so far as Brocq in saying that the regulation of the diet is the most efficacious internal treatment for eczematous patients.

The hypothesis of leprosy having been transmitted by food of any kind, in particular by fish, has not been established by further examination.

Boils are often ascribed to errors or deficiencies in diet. With our present knowledge of the pathogeny of boils, it is, to my mind, incredible how a crop of boils, as is stated on good authority, can arise through mere change of diet, e.g., a surplus of animal food.

In England the consumption of meat is $136 \mathrm{lbs}$. per head per annum. In France it is only $46 \mathrm{lbs}$. per head per annum. Are boils so much more common in England? Eczema affects the sexes almost equally, although men probably eat two-thirds of the total meat, and drink probably three-fourths of the total alcohol consumed in the United Kingdom.

If we direct our thoughts to determine what special articles in our dietary may be held responsible for harming the skin, we have not a long list, as will be gathered from the preceding remarks.

Coffee; tea, perhaps; highly spiced foods; excessive use of hard, salted meat; shell-fish; abuse of alcohol ; and, foods such as starch and other carbohydrates, which may lead to the production of excess of acids (acetic, lactic, butyric) in the intestines.

A wide-spread and deeply-ronted custom is the strict prohibition of salted food in diseases of the skin. For many years I have ignored this dictum, and neither my patients nor myself have had reason to regret the liberty accorded to them.

Chloride of Sodium is a very harmless salt, and some people with a weak digestion or a jaded appetite will relish and easily digest a thin slice of ham when the stomach would revolt against other meat.

Does alcohol in moderation cause any skin affection? That it is apt to aggravate itching and increase an already existing congestion of the skin is quite true.

Most of the Asiatic populations, with the exception of the Japanese and the Indian Parsees, drink no alcohol. Yet I do not know that this 
experiment, on the large scale, indicates any advantage to those races quoad the skin.

I cannot but believe that the ill effects of alcohol, and I may add of tobacco, are exaggerated by their extreme opponents, at any rate, as regards the skin.

Plenck (quoted by Bulkley) remarks of acne, "Plures curavi suadendo, ut vinum bibere incipiant."

Lastly, a word as to the practical outcome of all this.

How are we to intelligently answer the questions so often addressed to everyone of us by our clients, "What shall I eat?" "What shall I drink?"

In such cases as diabetes, gastric ulcer, and enteric fever there is a tolerable degree of unanimity in our answers.

But what about the slighter ailments and indispositions which constitute the bulk of our practice?

A large number of our patients with affections of the skin are not obviously out of health, and are well able for their day's work in the world. Yet these persons are apt to ponder over their health, put us through a catechism as to their diet, almost constrain us to go beyond our knowledge, and even glory in the dietetic chains which are fastened around them by their medical advisers.

Unluckily it sometimes happens that one practitioner's rules flatly contradict those of his neighbour, and so a shrewd patient is liable to arrive at the unpleasant conclusion that, as Sir William Roberts puts it, our notions on dietetics are little better than a farrago of whims and fancies.

We are too formal in our rules, and impose unnecessary and unmeaning restrictions. We prescribe diet by printed forms, making no allowance for idiosyncrasies, and giving even our educated patients little or no latitude or opportunity for exercising their own sense of what is good and what is bad for them.

In my judgment the main precept we need enjoin as a golden rule upon our patients suffering from diseases of the skin is moderation and temperance in all matters of eating and drinking, and especially as regards alcohol.

And we should seek to train the public to observe for themselves whether such and such an item of diet really agrees with them or not.

With all this borne in mind there is plenty of room for judicious 
advice tempered with common sense, and a hint or a suggestion is often better, although less showy, than the imposition of conventional rules. This latter course is, no doubt, sometimes requisite with the hypochondriac, the sensualist, or the careless, who will not listen to, or are incapable of understanding, the still small voice of healthy instincts and of personal experience.

To sum up in a few words :-

1. Very few skin diseases are directly traceable to dietetic causes, but improper diet may aggravate existing eruptions. Idiosyncrasy must be largely allowed for.

2. The diseases that may so arise are of a transitory character, and mostly belong to the class of erythemata.

3. Diet has very little influence in promoting the cure of cutaneous eruptions. The results are far behind popular expectations, even in such cases as acne rosacea, where we are led to hope for much.

4. Avoidance of alcohol, regulation of the bowels, and the cure of anæmia are of infinitely greater importance than special dieting in the management of diseases of the skin.

I may add that I have discussed this matter with my friend Dr. Wallace Beatty, and these propositions represent our joint views.

(For the ensuing Debate see page 330.) 